\title{
Ricardo Palma como crítico y editor en Flor de Academias y Diente del Parnaso
}

Por Manuel Pantigoso 
Poeta, crítico literario y de arte, dramaturgo, profesor universitario, promotor cultural y periodista. Doctor en Literatura y Filología y Doctor en Educación. Es Profesor Emérito de la Universidad Nacional Mayor de San Marcos y director de la Oficina Central de Extensión Cultural y Proyección Social de la Universidad Ricardo Palma. 
Luego de la breve introduccion, el articulo nombra los libros en los que Paima partictpa como editor y prologuista, poniendo énfasis en su vena critica. Se señalan luego las dos formas de escritura colonial a partir de Flor de Academias y Diente del Parnaso: una de loas y boatos y la otra extraida de la cantera popular: A continuación se estudia el ambiente en que fueron concebidas esas literatimas. las Academias y los poetas contertuitos de la Corte del Virrey; igualmente, algonos aspectos biográficos y la poesía de Caviedes, por ta que Palma sentía honda adntractón.

Palabras clave: critica, academia, gongorismo, criollismo, popular.

\section{Introducción}

Ricardo Palma es, junto con el Inca Garcilaso de la Vega, César Vallejo y Mario Vargas Llosa, uno de nuestros escritores más universales y celebrados, gracias a las Tradiciones Peruanas. Los estudios y las investigaciones sobre su obra se han venido multiplicando con el paso de los años y debido a la fecunda acción del Instituto Ricardo Palma, de su revista Aula Palma y de los Encuentros anuales denominados Re-Visión de las Tradiciones, impulsados por la universidad que lleva el nombre del ilustre escritor, se ha robustecido la bibliografía palmista desde diversos registros: la historia, la narrativa, la poesía, la sociología, la política, el periodismo, la educación, la lingüística. En esta oportunidad queremos enfocar el lado de la crítica y 
de las ediciones, que han sido, tal vez, las menos estudiadas. Dichos rubros se corresponden con los desvelos y los cuidados del llamado bibliotecario mendigo por salvaguardar aquellos textos dañados o casi perdidos, editándolos y estudiándolos en sustanciosos prólogos o en comentarios críticos.

En el aspecto de la crítica nos vamos a centrar en Flor de Academias y Diente del Parnaso, libro editado por Palma en 1899 que se refiere, primero, a la producción de los asistentes a la tertulia del virrey Manuel de Oms de Santa Pau, marqués de Castell-dos-Rius, entre septiembre de 1709 y marzo del año siguiente; y segundo, a la producción poética de Juan del Valle Caviedes.

\section{Las ediciones}

Uno de los grandes méritos que tiene Palma -además del eminentemente literario- es su amor por el pasado bibliográfico del Perú. Desde su posición como Director de la Biblioteca Nacional, él realizó una obra vasta de catalogación, de preservación y conservación de innumerables incunables, como se observa, por ejemplo, en la célebre sección "Papeles varios" que atesora una formidable riqueza de folletos y hojas sueltas, impresos en la época colonial y republicana, que Palma registra sumariamente pero que suministran el indicio para una futura y acaso posible reconstrucción del patrimonio bibliográfico peruano. En este sentido, el tradicionista editó varios libros que recopilan actas, apuntes históricos, memorias, que dan cuenta, sobre todo, de algunos aspectos de la historia en la Colonia. Vamos a nombrar los libros en donde está el invaluable servicio que presta Palma a la cultura peruana al salvarlos del olvido o de la depredación de la humedad o los insectos: 
1. Flor de Academias y Diente del Parnaso (1899). Esta edición dirigida por Palma es la que vamos a comentar en este trabajo.

2. Descripción del Perú (1901), por Tadeo Haenke, socio de las Academias de Ciencias de Viena y Praga.

3. Anales del Cuzco 1600 a 1750 (1901), que lleva un prólogo de Palma.

4. Apuntes Históricos del Perú y Noticias cronológicas del Cuzco (1902). Contiene, entre otras cosas, Apuntes Históricos, del general Manuel Mendiburu, sobre Costumbres e instituciones coloniales.

5. Anales de la Catedrat de Lima (1903), por el doctor José Manuel Bermudes, con prólogo de Palma.

6. Memorias Histórico Físico Apologéticas de la América Meridional que a la majestad del Señor don Carlos III dedica don José Eusebio de Llano Zapata (1904). Palma reprodujo un manuscrito de las memorias que compró en España.

\section{La crítica}

La crítica literaria de Ricardo Palma es uno de los registros que la crítica aún no ha abordado con profundidad. Uno de los medios que lo acercó tempranamente al mundo de la dilucidación de las ideas fue el periodismo, en donde ejerció diversas tareas vinculadas a las numerosas formas de participar en él: ayudante de cronista, redactor, crítico de teatro y crítico taurino, editorialista, corresponsal de la sección literaria, etc. Desde muy joven Palma empezó a hacer crítica literaria, como lo comprueba su folleto "Dos Poetas" publicado en 1961. El texto recoge dos ensayos que había publicado en la "Revista de Sub América" (Valparaíso). Los vates analizados son el 
argentino don Juan María Gutiérrez y la poetisa ecuatoriana Dolores Ventimilla. En sus libros Recterdos de España (1898) yen La bohemia de mi tiempo (1886), a la par que recoge semblanzas de época y personajes entrañables, aparece la constante vena crítica, presente con elegancia y profundidad. Sobre Zorrilla, dirá, por ejemplo, en el primer libro:

Para él los versos eran como el teclado de un piano, y a los heptasílabos y endecasílabos les daba cierto misterioso ritmo musical que deleitaba infinito (...) Con Zorrilla no ha desaparecido un hombre, sino una generación a la que él sirvió de símbolo en los ideales del arte y de lo bello. ${ }^{1}$

En La Bohemia de mi tiempo Palma agudiza el sentido histórico de su generación y remata en un ensayo lúcido que recoge hechos, causas y efectos para cernir con mayor agudeza y profundidad su instrumento crítico. Sabía "al dedillo" los gustos literarios de sus colegas:

Nosotros, los de la nueva generación, arrastrados por lo novedoso del libérrimo romanticismo, en boga a la sazón, desdeñábamos todo lo que a clasicismo tiránico apestara, y nos dábamos un hartazgo de Hugo y Byron, Espronceda, García Tassara y Enrique Gil. -Márquez se sabía de coro a Lamartine; Corpancho no equivocaba la letra de Zorrilla; para Adolfo García, más allá de Arolas no había poeta; Llona se entusiasmaba con Leopardi; Fernández, hasta en suenos, recitaba las doloras de Campoamor; y asi cada cual tenía su vate predilecto entre la pléyade revolucionaria del mundo viejo. De mí recuerdo que hablarme del Macias de Larra o de las Capilladas de Fray Gerundio, era darme por la vena del gusto. ${ }^{2}$

\footnotetext{
1 Ricardo Palma. Recterdos de España precedidos de ta Bohemia de mi tiempo. Lima, Imprenta La Industria, 1899: 147.

2 Ob. cit., p. 5.
} 
Donde la crítica se explaya a sus anchas es en las obras prologadas por Palma. Sería provechoso reunir en un libro aquellos prólogos que traen enjundiosos comentarios críticos de los autores estudiados. Hemos podido ubicar algunas obras que llevan palabras prologales del ilustre tradicionista; entre ellas podemos citar los siguientes:

\section{Teatro de Manuel A. Segura (1858).}

2. Lira Americana (1865). Colección de poesías de los mejores poetas del Perú, Chile y Bolivia, recopiladas por Palma, quien también hizo la semblanza crítica y biográfica de los poetas antologados.

3. Santa Rosa de Lima (1867). Poema heroico de don Luis Antonio de Oviedo y Herrera, Conde de la Granja. Contiene un juicio del poema por Ricardo Palma.

4. Perú, Tradiciones Cuzqueñas (1884). Leyendas biográficas y hojas sueltas de Clorinda Matto de Turner.

5. Artículos, poesías y comedias de Manuel Asencio Segura (1885). En su prólogo crítico sobre Segura, Palma estudia la evolución del teatro peruano hasta entonces.

\section{Un prólogo enjundioso}

El libro Flor de Academias y Diente del Parnaso ${ }^{3}$ se abre con un sustancioso prólogo de Palma que hace un repaso sumario de la

3 En 1898 el gobierno del Perú adquirió los manuscritos y obras impresas que formaban la librería personal de Félix Cipriano Coronel Zegarra Miembro Correspondiente de la Academia Española, recientemente fallecido. Entre esos mamuscritos se encontraban los de Flor de Academias y Diente del Pamaso, que reunidos en un solo volumen serían publicados por Palma al año siguiente, en 1899. EI 2009 la Universidad Ricardo Palma publicó una edición facsimilar preparada por Ricardo Silva-Santisteban. 
literatura de la Colonia a partir del siglo XVI hasta llegar a la primera década del siglo XVIII. Ahí encontramos un testimonio interesante de cómo el tradicionista pergeña algunas hipótesis osadas basándose en su conocimiento de la vida de aquella. época. Por ejemplo, presenta un conjunto de argumentos con la finalidad de sustentar la tesis de que Clarinda y Amarilis fueron en realidad hombres. Dice el tradicionista sobre la autora de Epistola a Belardo que "lo artificioso de las imágenes en el platonismo amoroso, más aún que la estructura de los versos, propia de pluma muy ejercitada en la métrica, nos están revelando a gritos a un hijo, y no de los peores, del dios Apolo"; ${ }^{4}$ igualmente encuentra raro el afán autobiográfico; dice, también, que las mujeres de esa época tenían poca instrucción como para hacer un poema "demasiado bien versificado". Luis Alberto Sánchez replica, con propiedad, que de ser aceptado esto ultimo habría que negar también la autenticidad de los versos de Sor Juana Inés de la Cruz, la poetisa mexicana casi contemporánea de la peruana. En realidad, este argumento de Palma debemos entenderlo desde la optica de su tiempo y no a la luz de los nuevos aportes de la investigación literaria. En el siglo XIX la crítica recién se estaba esbozando y Palma sería, acaso, uno de los primeros que empezaba a revisar, con agudo criterio, el panorama literario del país desde la Colonia hasta la República.

Desde el título - Flor de Academias y Diente del Parnaso- se abre una interrogante ¿́por qué el editor reunió dos libros en uno solo? ¿por qué no le dio a cada uno su independencia o autonomía? Algunos podrían sostener - con tino-que ambos textos guardan reciprocidad por tratarse de testimonios líricos pertenecientes a la época de la Colonia. Sin embargo, es posible considerar que hay, además, otra razón velada o camuflada que Palma no quiso explicitar porque se sobreentendía. Sus

4. En páginas prologales: XIII. 
páginas podrían mostrar los dos polos o dos extremos de la literatura colonial: uno sería la escrita con autenticidad, ironía y sarcasmo, sustentada en la cantera popular, y el otro, la animada con fuegos fatuos, con artificios de retórica, de loas y boatos, sustentada en la corte. A un lado estaría la figura de Juan del Valle y Caviedes y al otro la del virrey y sus contertulios, que eran poetas pertenecientes a la nobleza y muy reconocidos. La esencia popular de la palabra mordaz (diente) versus la faz aristocrática, retórica y refinada (flor). Por supuesto, Palma se afirmaría en la escritura de Caviedes a quien lo considera muy superior a aquellos "versadores" que siguieron a pie juntillas y de modo artificioso la moda cultista o gongorista. Por eso dirá del llamado poeta de la Ribera:

¿Es esto decir que el Perí no tuvo, en dos siglos, siquiera un poeta merecedor de renombre? Lejos de mí el desconsolador pesimismo. Tuvímoslo, de 1683 a 1691, en el limeño Juan de Caviedes, gran poeta satírico, que (como en más extenso juicio lo he expresado en otra oportunidad) si en erudición y doctrina no iguala ciertamente a Quevedo, se le aproxima en lo regocijado de su musa, en la travesura de su ingenio, en lo discreto del retruécano y hasta en las galas del bien decir. Los versos de Caviedes tienen, para mí, la corrección y la soltura que solo he encontrado en muy pocos de los humoristas contemporâneos. 5

Cierto "cosquilleo libidinoso" encuentra Palma en el libro de Caviedes. Creemos que al hablar del vate de la Colonia también está hablando de sí mismo en el siguiente fragmento:

Lo cierto es que Diente del Parnaso de Caviedes no es lectura que yo brindaría a una dama pudorosa, como no pondría en sus manos los romances picarescos, las jácaras y las sátiras

5 Prólogo a Flor de Academias y Diente del Pamaso, p. VII. 
del gran Quevedo, ni la Celestina, ni La Lozana andaluza, ni la tragicomedia de Calisto y Melibea, ni otros muchos de los libros clásicos, que son gala y orgullo de las castellanas letras. No siempre un literato ha de ser catedrático de moral austera. ${ }^{6}$

¿Acaso no está haciendo clara alusión a sus Tradiciones en Salsa Verde que las mantuvo inéditas por recato y pudor frente a las convenciones sociales de su tiempo? Podemos afirmar, eso sí, que en la lectura de la poesía de Caviedes Palma se reconoce dentro de esa línea o linaje criollista que proviene del autor de Diente del Parnaso.

Refiriéndose a los versos que se consigna en Flor de Academias, Palma tacha de mal gusto a sus autores achacándoles el abuso del hipérbaton y el alambicamiento en las expresiones. Por ello dirá: "Creo que fue el gongorismo, ese Moloch devorador de los más claros cerebros, el pecado en que anduvieron más empecatados los literatos de la tertulia palaciega". ? Ricardo Silva-Santisteban dirá en el pórtico del libro: "De cuando en cuando, sin embargo, en estas colecciones pobladas de abrojos se encuentran algunos poemas legibles, ingeniosos y hasta hermosos. Flor de Academias, con todo, es la colección de poesia lírica más importante como conjunto de poesía colonial peruana, así como Diente del Parnaso, la colección más importante de la poesía satírica.

Para calar en el plácido ambiente que rodeaba a la tertulia del Virrey señalemos que en aquella época era la literatura que se daba en el Virreinato del Perú, era naturalmente un reflejo de la que existía en España: Culteranismo (Góngora) y Conceptismo (Quevedo, Gracián), oscureciendo por igual la creación literaria barroca con una fuerte influencia italiana; y

\footnotetext{
6 Ibidem.

7 Recordemos que en 1662 Juan Espinoza Medrano, el Lunarejo, escribe su Apologético en favor de Luis de Góngora, documento de alta sensibilidad poética.
} 
desde el advenimiento de la dinastía de los Borbones en el trono español empezó a sentirse la influencia de los textos franceses. Era la época en la que los poetas y los aficionados a las musas se reunían en Academias, veladas o tertulias.

\section{Flor de Academias}

Las academias literarias que empezaron a florecer en la Colonia eran una moda proveniente del Siglo de Oro espanol. ${ }^{8}$ A su vez, estas son imitación de las academias italianas que nacen durante el Renacimiento, singularmente en la corte florentina de los Medici, en torno a Gituliano de Medici y, posteriormente, a Lorenzo de Medici, y en las que participaron Baltasar de Castiglione, Marsilio Ficino, Pietro Bembo, etc. Eran reuniones de poetas convocadas por un noble en su casa. Se dedicaban a departir sobre temas literarios y humanísticos y en general se proponía un tema para que los miembros compusieran poesías para la próxima reunión.

Una conocida academia literaria que se reunía en Lima fue la Academia Antártica, a cuyas reuniones asistían Diego de Aguilar y Córdoba, Cristóbal de Arriaga, Diego Dávalos Figueroa, Miguel Cabello Valboa, Pedro de Carbajal, Duarte Fernández, Francisco de Figueroa, Juan de Gálvez, Diego de Hojeda, Diego Mexía de Fernangil (Delio), Pedro de Montes de Oca, Pedro de Oña, Luis Pérez Angel, Cristóbal Pérez Rincón (Criselio), Juan de la Portilla y Agüero, Juan de Salcedo Villandrando y Luis Sedeño. Las reuniones se realizaron durante la última década del siglo XVI y la primera del siglo XVII.

8 Podemos citar a la Academia Mantuana, ante la que Lope de Vega leyó su Arte muevo de hacer comedias. 
Pero una de las más importantes academias de entonces fue la del Virrey Castell-dos-Rius, en donde se mezclaban escritores todavía culteranos y conceptistas con aquellos que recibían -aunque tardíamente- la nueva influencia francesa. Ricardo Palma da en el blanco al sef́alar la futilidad de la poesía colonial que daba primacía a la ornamentación de la forma y no a la esencialidad de la idea:

El Virrey marqués de Castell-dos-Rius era uno de los muchos literatos de aquel siglo que aspiraban a convertir la poesia en una especie de gimnasio intelectual, en el que mayor mérito se acordaba al vencedor de dificultades métricas que al que sobresalía por la altura y novedad del pensamiento. (...) En literatura, la idea vivía esclavizada al artificio de la forma, como, en política, la libertad atada al carro de la lejana metrópoli. (en Acta Segunda)

La primera reunión tuvo lugar el 27 de septiembre de 1709 y la última el 15 de mayo de 1710 , consagrada a exaltar la memoria del Virrey y mecenas que murió el 24 de abril de aquel año. Se tocaba música al empezar las reuniones, se representaban comedias y se leían las composiciones de cada uno. El Virrey señalaba el asunto sobre el que había de escribirse, así como el metro y el tiempo. Las actas de estas reuniones fueron recogidas y copiadas cuidadosamente por Diego Rodríguez de Guzmán, custodio de la Academia. ${ }^{9}$

Al final de cada sesión que aparece en Flor de Academias hay un comentario sintético de Ricardo Palma sobre el valor de cada una de estas jornadas poéticas. Leamos algunas:

Cierto que hay algo de frivolidad en gastar el fósforo del cerebro en tan fútiles producciones, pero es innegable que el

9 Tenía también el cargo de Capitán de Infantería española del tercio del presidio del Callao y Guarda mayor de la Real Casa de Moneda de Lima. 
ingenio de los poetas tenía que ponerse a prueba. Entre los enigmas leídos en esta sesión, los de nuestros compatriotas Peralta y licenciado Cascante, así como el de don Gerónimo de Monforte son, en mucho, superiores a los de los otros consocios. Rebosan donaire y agudeza. (en Acta Tercera).

Desentendiéndonos de la insustancial glosa, hay que convenir en que los académicos derrocharon ingenio y agudeza en los ovillejos. (en Acta Nona).

Lástima es que algunos de los autores hubieran hecho lujo de alambicamiento en los conceptos, y pecado otros de ampuloso gongorismo. (en Acta undécima).

En esta sesión, libres los ingenios de trabas forzadas, dan expansion a la musa en quintillas abundantes en buen humory en agudeza. (en Acta vigésima).

En estas veladas participaron escritores considerados como los mejores de su tiempo. Vamos a referirnos a algunos de ellos, auscultados por el lente crítico de Palma.

\section{José Bermúdez de la Torre y Solier}

José Bermúdez de la Torre y Solier (1661-1746) fue uno de los grandes animadores de la vida intelectual limeña. Durante su larga vida fue dos veces rector de la Universidad de San Marcos y participó en las Academias Literarias de su tiempo. Ejerció la abogacía, fue consultor de la Santa Inquisición, heredó de su padre el cargo de Alguacil Mayor de la Real Audiencia de Lima. Dentro de su fecunda producción destaca su largo poema "Telémaco en las islas de Calipso". Se caracteriza por la influencia virgiliana de varios episodios que estructuran su composición y por su gongorismo atenuado por influencias francesas. Había 
una especie de rivalidad - más lírica que de amistad- entre él y Pedro Peralta y Barnuevo. Palma recoge esta "rencilla" para realizar el siguiente comentario, entre irónico y gracioso:

Fue un poeta cortesano por excelencia, y su musa, como la de Peralta, se ocupó en lisonjear a virreyes y monarcas. Entre ambos se mantuvo viva competencia, y la opinión pública andaba dividida en lo de acordar al uno supremacía sobre el otro. Hoy hay que convenir en que Bermúdez, como poeta, sin serlo portentoso, es en mucho superior a Peralta. Por lo menos no es tan superlativamente dado al gongorismo y al conceptismo que hacen nebulosas, intraducibles al lenguaje llano, la mayor parte de las composiciones del autor de Lima fundada. A Bermúdez, de vez en cuando se le entiende; a Peralta, nunca; a lo sumo, se le adivina. ${ }^{10}$

\section{Luis Antonio de Oviedo Herrera y Rueda}

Luis Antonio de Oviedo Herrera y Rueda, Conde de la Granja (Madrid, 1636 - Lima, 17 17) fue un poeta y dramaturgo español que radicó en el Virreinato del Perú, especialmente en Lima. Fue el más vigoroso de los poetas participantes de la Academia del Palacio de Lima. Compuso dos libros de poemas de corte piadoso que le dieron fama: Vida de Santa Rosa de Santa María (1712) y el Poema sacro de la pasión (1717). De esta última obra Palma ofrece el siguiente comentario nada favorable:

"Dividido en siete estaciones de andanza o lectura muy fatigosa, como que son 4,976 los octosílabos y uno solo el asonante. El conde era lo que se llamaba hombre erudito y de vivaz fantasía, si bien como poeta afean sus versos las extravagancias culteranas a que era muy propenso". ${ }^{11}$

10 Ob. cit., p. XVIII.

$11 \mathrm{Ob}$. cit., p. XVII. 


\section{Antonio de Zamudio y de las Infantas}

Antonio de Zamudio y de las Infantas (Lima, 1661-1730), fue un noble, militar y poeta criollo de origen andaluz, que ocupó altos cargos militares en el Virreinato del Perú. Además de que algunas de sus composiciones están en Flor de Academias, un soneto suyo aparece en La galeria de las mujeres fuertes, escrita en francés por el jesuita Pierre Le Moyne y traducida al castellano por Fernando Bravo de Lagunas y Bedoya. Con cierta sorna Palma dice de él que "escribía versos cuando las musas andaban de bureo lejos del Parnaso".

\section{Pedro Peralta y Barnuevo (Lima, 1663-1743)}

De recia personalidad, signada por una extraordinaria erudición su nombre está ligado a la poesía, al teatro, a la historia, a las matemáticas, a la astronomía, a la ingeniería (traza las murallas de Lima), al ensayo, etc, etc. Su condición de políglota (hablaba siete idiomas) y de enciclopedista, que es asombrosa, lo retrata mury bien, a él y a su época.

A pesar de que Palma encuentra elevados méritos en el llamado Doctor Océano por su vastedad de conocimientos, no comulga con su poética. Dijo, tal vez muy a su pesar: "El Arte, la estética literaria no pueden, en desapasionada y concienzuda crítica, darle puesto de honor entre los favorecidos por el cielo con los dones del sentimiento y de la expresión poética". ${ }^{2}$

Respecto a su poema Lima Fundada que es la obra fundamental de Peralta como poeta, no le tuvo tampoco en alta estima. El texto es una crónica rimada en donde aparecen Pizarro y los españoles, muy elogiados en desmedro de los indios cuya historia

12 Ob, cit., p. XIX. 
- dice Palma - parece desconocer, pasando por la descripción de templos, fortalezas, palacios; y también las luchas de Huáscar y Atahualpa; y el relato de la prisión del Inca, hasta llegar al origen mismo del poema que es la fundación de Lima en donde hay datos importantes sobre los personajes de la época. Toda la obra es calificada como muy irregular poéticamente hablando. Hay sin embargo destellos que merecen ser destacados, como la siguiente octava referida al viaje de los Conquistadores:
Mas ya por senda nunca descubierta
la proa entrega al húmedo elemento
siendo en la duda en que fluctía incierto
de la nave de otro golfo el pensamiento:
pero, derrota de valor más cierta,
pero de fe la lleva mejor viento:
$\mathrm{Y}$ siendo de sí misma astro la quilla, al rumbo no navega sino brilla.

Refiriéndose a Lima fundada, Palma dirá con sinceridad lo siguiente:

\begin{abstract}
A su conceptuoso poema "Lima fundada", le falta el quid divinum, el perfume poético. Sus octavas, soberanamente gongóricas, carecen del ritmo musical de la poesía, y revisten caracteres de mala prosa rimada. Sus imágenes no son flores nacidas en cármenes deliciosos y mecidas por la brisa tropical, sino flores de conservatorio, sin aroma ni colores vivos. ${ }^{13}$
\end{abstract}

Otros integrantes de estas tertulias fueron: Miguel Sáenz Cascante, presbitero, Fr. Agustín Sanz, de la Orden de Mínimos, calificador del Santo Oficio y confesor del Virrey, Juan Eustaquio Vicentelo y Toledo, marqués de Brenes, Juan Manuel de Rojas

13 Ibidem. 
y Solórzano, secretario del Virrey, Matías Ángeles de Meca, gentilhombre de cámara del Virrey y Jerónimo Monforte y Vera.

Para acercarnos más al espíritu de estos personajes mostremos un texto que aparece en Flor de Academias, cuyo autor es Miguel Cascante. En rápidos y líricos pincelazos describe a cada uno de los contertulios:

Del Padre Sanz escuché

doctos y graves conceptos, y en sus discursos hallé los soberanos afectos que son la luz de la fe. A Brenes vi transformado en misionero elocuente, poniendo el polvo en la frente

a cualquier suerte o estado con devocion reverente. Rojas, aunque estuvo ausente, mereció por la armonía de su delicada mente, que los cisnes a porfía le aplaudan como presente. Bermídez, con el primor de su natural acierto, como cisne superior logra armonía y concierto voz, pluma, aliento y rumor. Peralta, con voz severa gritos da a los huesos secos, diciendo lo que el hombre espera cuando, en esos secos huecos, se esconde la Primavera. Monforte con elocuencia natural y no precisa, 
de nuestro bien nos avisa, y con grande persistencia nos ha puesto la ceniza. Mathias, cual dulce Orfeo, académico se adimira, pues cuando pulsa la lira es cuando logra el trofeo en el que sus cantos mira. De la música percibo las letras y los compases. y de su armonía recibo, en bien cortesanas frases, el aliento con que vivo. Solo es sordo el que no atiende y no lo es aquel que escucha; entre el que oyó y no lo entiende, y el que es sordo y lo comprende, es la diferencia mucha.

(Acta décima octava, fragmento del poema de Miguel Cascante, en Flor de Academias, pp. 296-297.)

\section{Diente del Parnaso, de Juan del Valle Caviedes}

Podemos nombrar muchos nombres de la Colonia que Ricardo Palma evoca en sus Tradiciones: Bernardino Ruiz, el Arzobispo Barroeta, el jesuita Buendia, Luis Oviedo y Herrera, dona Violante de Cisneros, doña María Manuela Carrillo Andrade y Sotomayor, don Juan Julián Capetillo, don Basilio García Ciudad, don José Martín de Aguilar, etc. Junto a ellos aparecen líricos de fuste, como Juan del Valle Caviedes, Diego de Ojeda, Amarilis, el Príncipe de Esquilache, Trinidad Fernández, etc. Sobre el primero - Caviedes-Palma manifiesta una fervorosa admiración no solo detectable en sus asedios críticos, sino 
también, por ese ascendiente espiritual y "criollista" que le viene precisamente a través del autor de Diente del Parnaso. Palma tendría referencia de Caviedes desde muchos años atrás: "ya en 1873, en muy incorrecta edición, habíamos dado a conocer las producciones de Caviedes que, hasta aquel año, permanecían inéditas". ${ }^{14}$

Caviedes fue un satírico de gran agudeza, hermano espiritual de Pancho Fierro. Aunque nacido en Porcuna, Andalucía (¿1652?) fue trasladado a Lima a muy tierna edad. Con él nace el llamado criollismo, ágil y vivaz, que sabe percibir y describir lo ridículo de la sociedad. El chiste, la broma, la anécdota ligera y picante, no exenta de procacidad, el cuento agudo o frase de sentido equívoco y gracioso, lo caracterizan. Pero también es uno de los pocos poetas de la época que tiene conciencia de la importancia de la poesía, no como un adorno retórico sino como elemento de crítica social realista y descamada, de liberación y desalienación frente al mundo corrupto e inmoral, que alcanzaba, inclusive, a los conventos, y del cual el pueblo empezaba a darse cuenta antes de que se iniciara la rebeldía. Desde este punto de vista, el notable poeta de la Colonia puede ser considerado como el primer revolucionario de la literatura peruana. Leamos este texto, titulado "Privilegios del pobre", en donde el sentido estético colinda con el ético, y la correlación poesía-sociedad aparece sin amaneramientos para dar un vivo retrato de la época:

El pobre es tonto, si calla;

y si habla es un majadero;

si sabe, es un hablador;

y si afable, es embustero;

si es cortés, entrometido;

cuando no sufre, soberbio;

14 Ob. cit. 335 . 


\author{
cobarde, cuando es humilde: \\ y loco cuando es resuelto; \\ si, valiente, es temerario: \\ presumido, si es discreto; \\ adulador, si obedece; \\ y si se excusa, grosero; \\ si pretende, es atrevido; \\ si merece, es sin aprecio; \\ su nobleza es nada vista, \\ y su gala sin aseo; \\ si trabaja es codicioso. \\ y por el contrario extremo \\ un pérfido si descansa... \\ Miren si son privilegios!
}

("Privilegios del pobre", en Diente del Parnaso, p. 457.)

Palma, aguzando su fino sentido crítico, le da a la poesía de Caviedes el valor de lo clásico, de su permanencia esencial en el tiempo. De allí que se le siente actual. No es el poeta que se empalaga en el floreo lingüístico. Al contrario, ahonda en las zonas esenciales en el decir de la palabra. Palma ofrece este comentario certero del cual han partido muchos críticos contemporáneos:

Caviedes no se contaminó con las extravagancias y el mal gusto de su época, en que no hubo alumno de Apolo que no pagase tributo al gongorismo.

En la regocijada musa de nuestro compatriota no hay ese alambicamiento culterano, esa manía de lucir erudición indigesta, que afea tanto las producciones de los mejores ingenios del siglo XVIII. A Caviedes lo salvarán de hundirse en el osario de las vulgaridades, la sencillez y la naturalidad de sus versos, y la ninguna pretensión de sentar plaza de sabio. 
Décimas y romances tiene Caviedes tan frescos, tan castizos, que parecen escritos en nuestros días. (...) En el género festivo epigramático, no ha producido hasta hoy la América española un poeta que aventaje a Caviedes ${ }^{n}$. . $^{-5}$

Palma reproduce en su prólogo aspectos biográficos y psicológicos de Caviedes. Indica, por ejemplo, dos momentos en la vida del autor: antes y después de sus desgracias y sinsabores; igualmente revela su tono festivo y amargo pero siempre satírico que lo ha de caracterizar permanentemente.

Enfermo, pobre y envejecido, habiendo tenido cinco hijos y casado por segunda vez, Caviedes pasó sus últimos años en una de las barracas o tienduchas de baratijas que existían en la Plaza de Armas, conocidas con el nombre de Cajones de la Ribera. De aquí viene su apelativo de Pota de la Ribera, porque en ese lugar alcanzó su mejor fama de poeta risueño, que sabía caracterizar a todas las figuras típicas de la ciudad mientras continuaba atacando a los médicos por la proximidad de su muerte: "Mátenme de sus palabras/ pero no de sus recetas,/ que así matarme es venganza/ pero no muerte a derechas./ (...) iMe moriré! buen provecho./ iMe moriré! en hora buena; peor sin médicos cuervos/ junto de mi cabecera". Y se murió, quizá rodeado de sus eternos enemigos, antes o muy poco después de los 40 anios, entre 1692 y 1695 .

Frente a lo chocante que puede sonar su poesía para el academicismo imperante, el tradicionista apunta: "El Diente del Pamaso escandalizará oídos susceptibles, sublevará estómagos delicados y no faltará quien lo califique de desvergonzadamente inmoral". ${ }^{16}$ Sin embargo, Caviedes vive $y$ ha sabido vivir porque la sustancia que edulcora sus versos es de la sangre que florece 
del pueblo. De allí esta categórica verdad con que el autor de las Tradiciones celebra a su poeta favorito:

Pero por delicados y quisquillosos que seamos, en estos tiempos de oropel y de máscaras; por mucho que pretendamos disfrazar las ideas, haciendo para ellas antifaces de las palabras, hay que reconocer que, en la lengua de Castilla, tiene Caviedes pocos que lo superen en donaire y travesura. ${ }^{17}$

Palma también tiene en sus tradiciones ese espíritu zumbón y travieso, con grandes dosis de poesía. De allí su afinidad y su devoción hacia este "poeta de la Ribera" Hay un texto muy conocido de Caviedes que recoge uno de los temas más característicos de su producción literaria: la crítica acerba a los médicos en general:

El mundo todo es testigo.

Muerte de mi corazon.

que no has tenido razón

de portarte así conmigo.

Repara que soy tu amigo,

y que de tus tiros tuertos

en mí tienes los aciertos;

excísame la partida,

que por cada mes de vida

te daré treinta y un muertos.

Muerte! Si los labradores

dejan siempre qué sembrar

¿cómo quieres agotar

la semilla de doctores?

Frutos te damos mayores;

pues, con purgas y con untos.

17 Ibidem. 
damos a tu hoz asuntos

para que llenes los trojes.

y por cada doctor coges

diez fanegas de difuntos.

No seas desconocida

ni contigo uses rigores, pues la Muerte sin doctores

no es muerte, que es media vida.

Pobre, ociosa y desvalida

quedarás en esta suerte, sin que tu aljaba concierte, siendo en tan grande mancilla una pobre muertecilla o Muerte de mala muerte. Muerte sin médico es llano que será por lo que infiero, mosquete sin mosquetero, espada o puñal sin mano. Este concepto no es vano; porque aunque la muerte sea tal, que todo cuanto vea se lo lleve por delante, que a nadie mata es constante si el doctor no la menea. Muerte injusta! Tú también me tiras por la tetilla; más ya sé no es maravilla pagar mal el servir bien. Por Galeno, juro a quien venero, que si el rigor no conviertes en amor sanándome de repente, y muero de este accidente, que no he de ser más doctor. 
Mira que en estos afanes. si así a los médicos tratas. han de andar después a gatas los curas y sacristanes. Porque soles ni desmanes, la suegra y el suegro peor fruta y nieve sin licor, bala, estocadas y canto, no matan al año tanto como el médico mejor.

(Décimas, "Coloquio que tuvo con la muerte un médico moribundo", en Diente del Parnaso, p. 361.)

\section{Conclusiones}

Ricardo Palma fue uno de los primeros en el Perú en abrir la senda de los estudios críticos. Como editor se preocupó en hacer el estudio y los comentarios de las obras publicadas. Fue el primero en estudiar en forma panorámica la literatura de la Colonia así como de los personajes importantes como el propio Caviedes; y también de Segura o Clorinda Matto de Turner. Más allá del enjuiciamiento positivo o negativo que hace de los escritores de la Colonia, lo cierto es que la presencia de todos ellos demuestra el versado conocimiento crítico que tenía de esta literatura.

Palma, al ver en la poesía popular de Caviedes el reverso de esa poesía alambicada y barroca de los escritores de las veladas dirigidas por el Virrey marqués de Castell-dos-Rius, demuestra una madurez crítica necesaria para empezar a juzgar la obra literaria. 


\section{Bibliografía}

HOLGUIN Cayo, Oswaldo. Ricardo Palma. Lima, Empresa Periodística Visión Peruana, 1987.

- Tiempos de Infancia y Bohemia de Ricardo Paima (1833-1860). Lima, Fondo Editorial de la Pontificia Universidad Católica del Penú, 1994.

MIRÓ, César. Los oficios de Don Ricardo. Lima, Ediciones Cuper Perú, 1994.

PALMA, Ricardo.Recuerdos de España precedidos de la Bohemia de mi tiempo. Lima, Imprenta La Industria, 1899.

SÁNCHez, Luis Alberto. Manuel González Prada. Obras. Tomo II, Lima, Ediciones COPÉ, 1986. 